www.jmscr.igmpublication.org

Impact Factor 5.84

Index Copernicus Value: 83.27

ISSN (e)-2347-176x ISSN (p) 2455-0450

crossref DOI: _https://dx.doi.org/10.18535/jmscr/v5i2.116

\author{
Journal Of Medical Science And Clinical Research \\ IGM Publication \\ An official Publication of IGM Publication
}

\title{
Role of Fetal MRI in detection of CNS anomalies
}

\author{
Authors \\ Dr Karanbir S Bajwa ${ }^{1}$, Dr Sanjay B Shahu ${ }^{2}$, Dr Avinash P Dhok ${ }^{3}$, \\ Dr Sushupti M Chaukhande ${ }^{4}$, Dr Purva M Agarwal ${ }^{5}$, Dr Gurnihal S Chawla ${ }^{6}$ \\ $1,4,5$ Junior Resident, ${ }^{2}$ Associate Professor, ${ }^{3}$ Professor \& Head, ${ }^{6}$ Senior Resident \\ $1,2,3,4,5,6$ Department of Radiodiagnosis, NKP Salve Institute of Medical Sciences \& Research Centre, \\ Lata Mangeshkar Hospital, Nagpur \\ Corresponding Author \\ Dr Karanbir S Bajwa \\ Lata Mangeshkar Hospital, Hingna Road, Nagpur PIN- 440019 \\ Email: karan.bajwa87@gmail.com, Mobile Number-9158023311
}

\begin{abstract}
Context: Congenital malformation is a stimulating problem for research. The commonest of these are CNS anomalies (1). The abnormalities detected on Ultrasound may at times be very subtle or inconclusive. In such cases, several studies have shown that MRI is a helpful modality.

Aims: 1.To establish role of MRI in detection and evaluation of CNS anomalies.

2. To assess whether fetal MRI provides additional information to findings detected on USG.

Settings and Design: Cross sectional study

Methods and Material: All pregnant women referred to our department within 2 years, were examined by USG. 36 patients with fetal CNS anomalies detected on USG were subsequently examined by MRI and results were analyzed statistically.

Statistical Analysis Used: Quantitative and Qualitative data are presented with the help of Mean and Standard deviation \& frequency and percentage table respectively. Association among study groups is assessed by Fisher test, student 't' test and Chi-Square test. 'p' value less than 0.05 is taken as significant.

Results: Ultrasound detected and suspected anomalies in 36 cases of CNS, which were subsequently confirmed or further characterized with some additional information obtained or were concordant on MRI. There were also some cases that turned out to be normal on MRI and some where the MRI findings were totally discordant with the USG findings.

Conclusions: MRI is superior to USG in diagnosing CNS anomalies of the fetus. MRI can add additional diagnostic information to sonography in fetuses for which prenatal intervention is being considered.

Keywords: CNS anomalies, MRI, USG.
\end{abstract}

\section{Introduction}

Congenital malformation is a stimulating problem for research study because of the high frequency of its occurrence and the devastating effect it may have on the individual and his family. A study conducted in Giza, Egypt on 3,000 live and stillbirth babies, showed that $3.17 \%$ (95 babies) had congenital anomalies, the commonest being CNS anomalies constituting about $1 / 3$ of all malformations (1). Prenatal diagnosis of congenital anomalies is a 
difficult problem to which ultrasound has made substantial contributions. This examination by a skilled operator, in most cases, provides adequate information regarding fetal morphology, its environment, and its well-being. The quality of Ultrasound however, is adversely affected by factors such as maternal obesity, unfavorable fetal position, multiple gestations, decreased amniotic fluid or the near-field reverberation artefact ${ }^{(2)}$.

The abnormalities detected on Ultrasound may at times be very subtle or inconclusive. Such abnormalities can be confirmed or ruled out by MRI. In some cases, additional findings detected with MRI often help in arriving at a definitive diagnosis, which is necessary for parental counseling and for guiding management. Fast $\mathrm{T} 2 \mathrm{~W}$ sequences form the basis of fetal MRI.

Moreover, prenatal US has a limited specificity in diagnosis of fetal anomalies. For example, ventriculomegaly is a common end point for various pathologic processes including hydrocephalus, cerebral dysgenesis, and atrophy or encephalomalacia. Differential diagnosis in such cases is important. ${ }^{(3,4)}$ In such cases, several studies have shown that MRI is a helpful modality. (5,6,7) Magnetic resonance imaging (MRI), provides a highly accurate depiction of the morphological changes of development in the normal brain and in fetal brain disorders. Thus, MRI can provide improved anatomical resolution. Another advantage of MRI is that intracranial brain imaging is not impacted by the calvaria, which allows clear identification of the cortex and subarachnoid space. ${ }^{(8,9)}$

Superior soft tissue contrast and the ability to depict sulcation and myelination are the strengths of MRI

Fetal motion was a limiting factor in early studies however; the fast MRI sequences can obtain images in just $430 \mathrm{~ms}$ and subsequently can obtain images required for diagnosis. Real time MRI allows almost continuous imaging of the moving fetus. ${ }^{(10,11)}$

\section{Material and Methods}

All Pregnant women referred to our Department for Anomaly Scan were taken as subjects for the study. All the norms stipulated in the PC-PNDT act were followed. The patients were subjected for Transabdominal Sonography for ante natal scan.If the USG findings were inconclusive or unconfirmed then the patients were further evaluated using Magnetic resonance Imaging and findings were confirmed on magnetic resonance imaging. Imaging was done with 1.5 Tesla MRI machine and the sequences were selected as required. The sample size was 36.

SEQUENCES used FOR MR IMAGING were:

- T2 single-shot fast spin echo (SSFSE) sequence.

-FIESTA

- SPGR

Appropriate sequences were used in all the three planes that included axial, sagittal and coronal plane. Postnatal outcome was obtained wherever it was possible.

\section{Inclusion Criteria}

- All pregnant women with suspected CNS fetal anomaly on Ultrasound scan.

- Pregnant women with previous history of CNS fetal anomalies.

\section{Exclusion Criteria}

- Claustrophobia.

- Metallic implants insertion, cardiac pacemakers and metallic foreign body in situ.

- Not willing to give consent.

\section{Results}

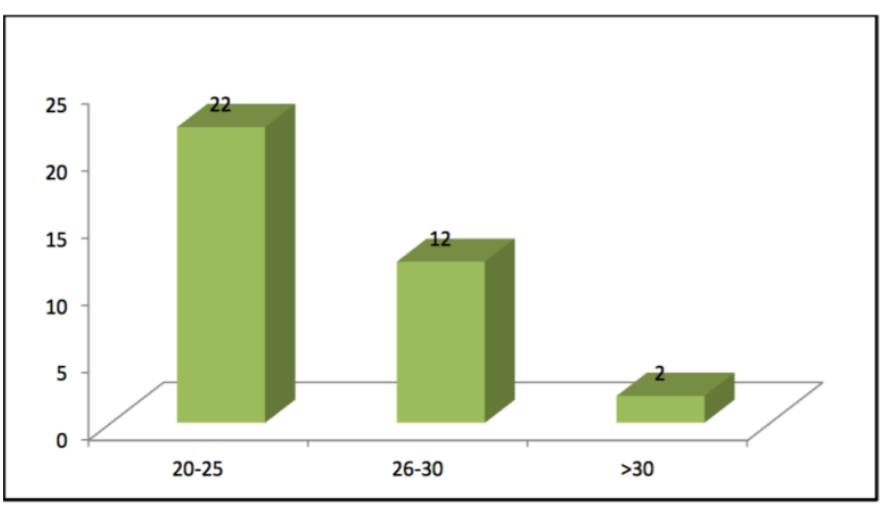

Majority that is 22 of the patients were in the age group of 20-25 years followed by 12 patients in the age group of 26-30 years and 2 patients greater than 30 years of age group. The mean age of patients was $24.83 \pm 3.10$ years 


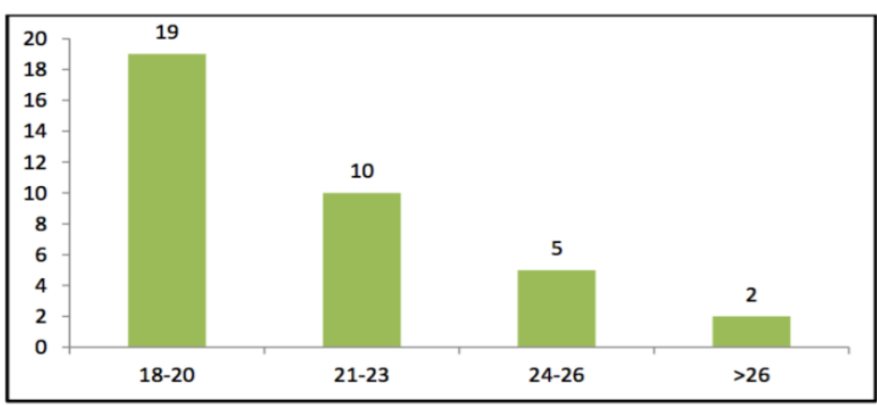

19 of the cases in my study were in the gestational age of 18-20 weeks followed by 10 cases in the gestational age of 21-23 weeks, 5 cases in the gestational age of 24-26 weeks and 2 cases of gestational age greater than 26 weeks.

Ultrasound detected and suspected anomalies in 36 cases of CNS, which were subsequently confirmed or further characterized with some additional information obtained or were concordant on MRI. There were also some cases that turned out to be normal on MRI and some where the MRI findings were totally discordant with the USG findings.

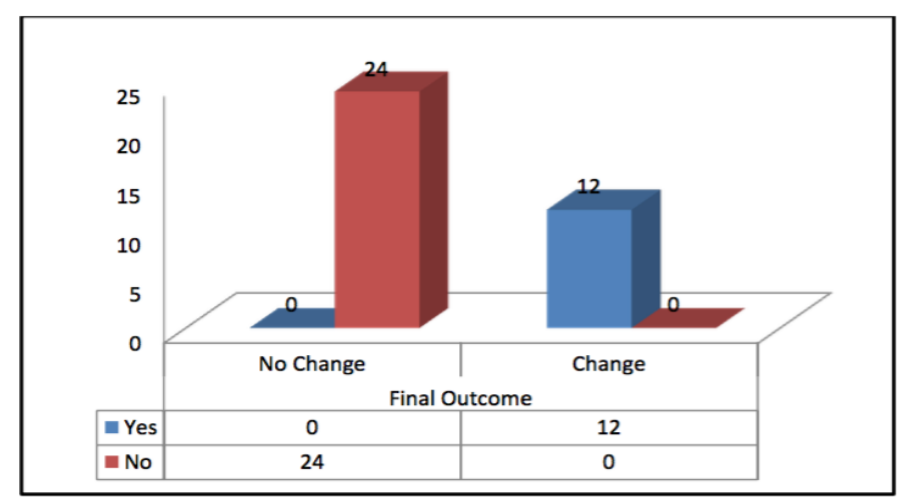

There was change in the final outcome in $12(33.4 \%)$ cases whereas there was no change in the final outcome in the remaining 24 patients. This difference was statistically significant $(p<0.05)$.

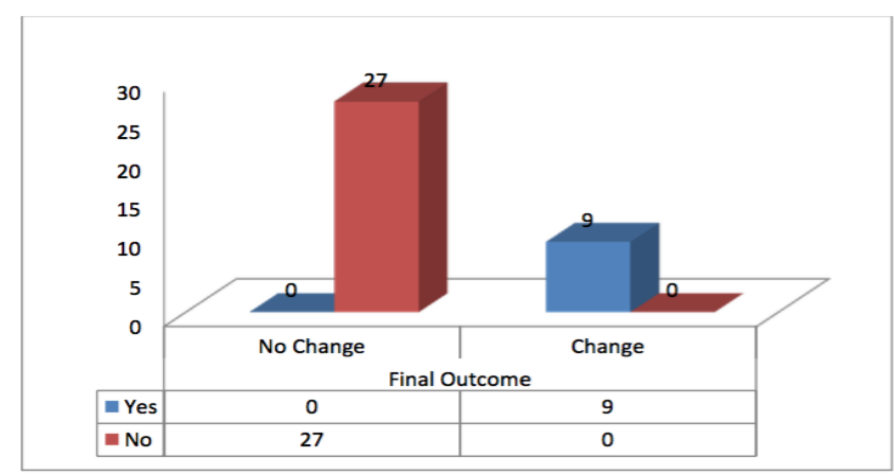

MRI played an additive role and further characterization in $9(25 \%)$ cases while there were no additional characterizations and additive role in remaining $27(75 \%)$ cases. This difference was statistically significant $(\mathrm{p}<0.05)$.

\section{Discussion}

We prospectively examined 36 fetuses of all pregnant women with confirmed antenatal congenital anomaly or subsequent diagnosis of CNS anomaly after Anomaly Scan.

\section{Distribution of cases according to Ultrasound Diagnosis}

In the present study, there were $5(13.8 \%)$ cases of Anencephaly, $3(8.3 \%)$ cases of Ventriculomegaly and $2(5.6 \%)$ cases each of Hydrops fetalis and isolated ventricular prominence. Ultrasound Diagnosis could not confirm results of 9 cases. It was suspected that $2(5.6 \%)$ cases were of Corpus callosum agenesis and 1 (2.8\%) case each of Abnormal curvature of lumbar spine, Cerebellar vermis dysgensis, Dandy Walker, Grossly dilated ventricles with cerebellar vermis dysgensis, Microcephaly, ventriculomegaly and Corpus callosum agensis, Occipital meningocele cerebellar vermis dysgensis and Posterior fossa cyst with grossly dilated ventricles cerebellar hypoplasia Distribution of cases according to MRI Diagnosis In the present study, there were $5(13.8 \%)$ cases of Anencephaly and $2(5.6 \%)$ cases each of Arnold chiari malformation II, Hydrops fetalis, one case each of bilateral open lip schizencephaly, lobar holoprosencephaly and arachnoid cyst. .9 (25\%) cases were detected as normal. 9 unconfirmed cases in Ultrasound Diagnosis were confirmed in MRI findings with further characterization in 4 cases. Two unconfirmed cases of Cerebellar vermis dysgensis and Corpus callosum agenesis were diagnosed as Normal in the MRI findings. We evaluated the proportional change in final outcome in the form of change in prognosis or change in diagnosis due to additional information provided by MRI. This gave us an objective evaluation of the significance of performing an MRI and the effect that this information had in management of the pregnancy. 
Our results showed that Ultrasound detected and suspected anomalies in 36 cases of CNS, which subsequently confirmed or further characterized and were concordant on MRI. In 16 out of 36 cases, the findings on Ultrasound and MRI were concordant. In 9 out of 36 cases suspected on Ultrasound were subsequently found to be normal on MRI. In rest of remaining cases, there was definite confirmation , characterization and additional information obtained on MRI which further elucidated the USG findings and hence helped in the decision making process for the parents giving them a clearer picture of the prognosis.

\section{Distribution of cases according to Ultrasound Diagnosis}

\begin{tabular}{|l|l|l|}
\hline Ultrasound Diagnosis & $\mathrm{N}$ & $\%$ \\
\hline Abnormal curvature of lumbar spine?? & 1 & $2.8 \%$ \\
\hline Abnormal gyri & 1 & $2.8 \%$ \\
\hline Anencephaly & 5 & $13.8 \%$ \\
\hline Anencephaly with spine deformity & 1 & $2.8 \%$ \\
\hline Arachnoid cyst & 1 & $2.8 \%$ \\
\hline Arnold chiari malformation II & 1 & $2.8 \%$ \\
\hline Cerebellar vermis dysgensis ?? & 1 & $2.8 \%$ \\
\hline Chiari malformation II & 1 & $2.8 \%$ \\
\hline Colpocphaly & 1 & $2.8 \%$ \\
\hline Corpus callosum agenesis?? & 2 & $5.6 \%$ \\
\hline Dandy Walker Malformation?? & 1 & $2.8 \%$ \\
\hline Dilated lateral ventricle & 1 & $2.8 \%$ \\
\hline Dilatation of right ventricle & 1 & $2.8 \%$ \\
\hline $\begin{array}{l}\text { Gross Hydrocephalus with } \\
\text { thinning, Bilateral open lip schizencephaly }\end{array}$ & 1 & $2.8 \%$ \\
\hline $\begin{array}{l}\text { Grossly dilated ventricles with ??cerebellar } \\
\text { vermian dysgensis }\end{array}$ & 1 & $2.8 \%$ \\
\hline Hydrops fetalis & 2 & $5.6 \%$ \\
\hline Isolated ventricular prominence & 2 & $5.6 \%$ \\
\hline Kinking in cervico-dorsal region & 1 & $2.8 \%$ \\
\hline Kyphoscolosis of thoracic and lumbar spine & 1 & $2.8 \%$ \\
\hline & 1 & $2.8 \%$ \\
\hline Long segment meningocele & 1 & $2.8 \%$ \\
\hline $\begin{array}{l}\text { Microcephaly, ventriculomegaly and Corpus } \\
\text { callosum agenesis?? }\end{array}$ & 1 & $2.8 \%$ \\
\hline Occipital encephalocele & 1 & $2.8 \%$ \\
\hline $\begin{array}{l}\text { Occipital meningocele??cerebellar vermis } \\
\text { dysgensis }\end{array}$ & 1 & $2.8 \%$ \\
\hline Open lip schizencephaly & 1 & $2.8 \%$ \\
\hline $\begin{array}{l}\text { Posterior fossa cyst with grossly dilated } \\
\text { ventricles ??cerebellar hypolasia }\end{array}$ & 1 & $2.8 \%$ \\
\hline Ventriculomegaly & 3 & $8.3 \%$ \\
\hline Total & 36 & $100 \%$ \\
\hline
\end{tabular}

Distribution of cases according to MRI Diagnosis

\begin{tabular}{|l|l|l|}
\hline MRI Diagnosis & $\mathrm{N}$ & $\%$ \\
\hline Abnormal curvature of lumbar spine & 1 & $2.8 \%$ \\
\hline Abnormal gyri with liscencephaly & 1 & $2.8 \%$ \\
\hline Anencephaly & 5 & $13.8 \%$ \\
\hline Anencephaly with spine deformity & 1 & $2.8 \%$ \\
\hline Arachnoid cyst & 1 & $2.8 \%$ \\
\hline Arnold chiari malformation II & 2 & $5.6 \%$ \\
\hline $\begin{array}{l}\text { Arnold chiari malformation II and bilateral } \\
\text { club foot }\end{array}$ & 1 & $2.8 \%$ \\
\hline Bilateral open lip schizencephaly & 1 & $2.8 \%$ \\
\hline Corpus callosum agenesis & 1 & $2.8 \%$ \\
\hline Dandy walker malformation & 2 & $5.6 \%$ \\
\hline $\begin{array}{l}\text { Grossly dilated ventricles, cerebellar } \\
\text { hypoplasia and club foot }\end{array}$ & 1 & $2.8 \%$ \\
\hline Hydrops fetalis & 2 & $5.6 \%$ \\
\hline $\begin{array}{l}\text { Kyphoscolosis of thoracic and lumbar spine } \\
\text { and horse shoe kidney }\end{array}$ & 1 & $2.8 \%$ \\
\hline Kyphosis & 1 & $2.8 \%$ \\
\hline Lobar holoprosencephaly & 1 & $2.8 \%$ \\
\hline $\begin{array}{l}\text { Microcephaly, ventriculomegaly and Corpus } \\
\text { callosum agenesis }\end{array}$ & 1 & $3.13 \%$ \\
\hline Normal & 9 & $25 \%$ \\
\hline Occipital encephalocele & 1 & $2.8 \%$ \\
\hline Occipital meningocele, cerebellar vermis & 1 & $2.8 \%$ \\
\hline Open lip schizencephaly & 1 & $2.8 \%$ \\
\hline Ventriculomegaly & 1 & $2.8 \%$ \\
\hline Total & 36 & $100 \%$ \\
\hline
\end{tabular}

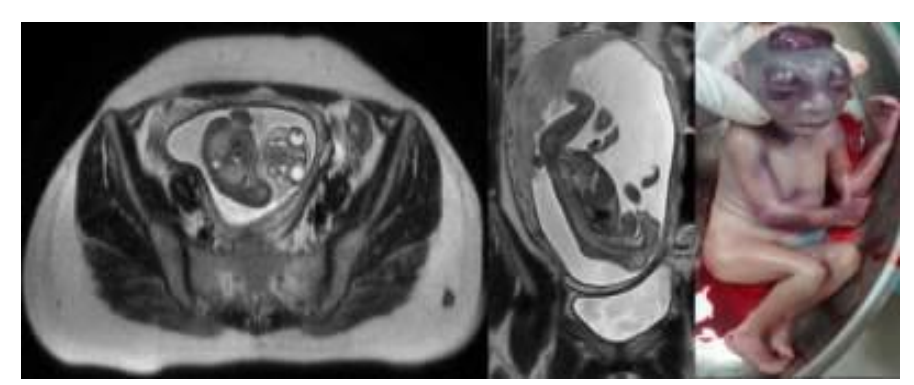

Image 1) MRI of fetus axial and sagittal T2WI showing frog eye apperance with absence of skull vault, suggestive of anencephaly.

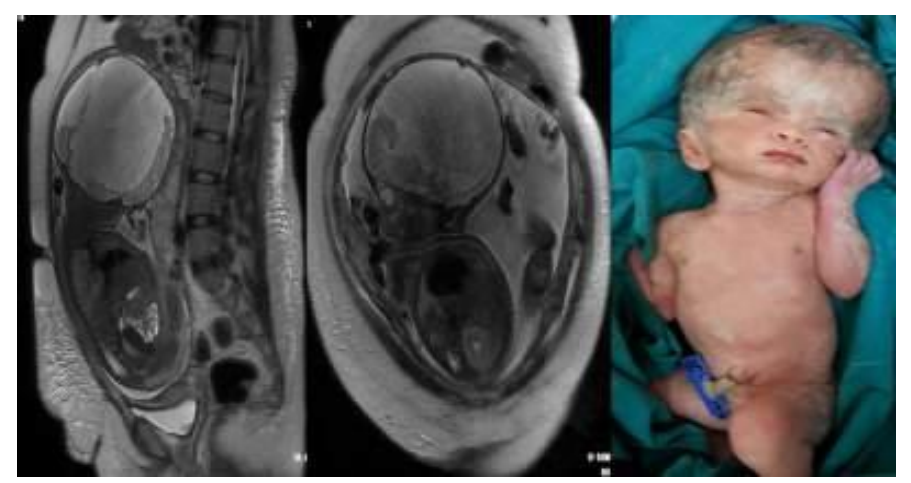

Image 2) MRI of fetus axial and coronal T2W images showing increased head circumference with grey matter lined defect with shrinking of brain 
parenchyma and crowded cerebellum suggestive of open lip schizencephaly.

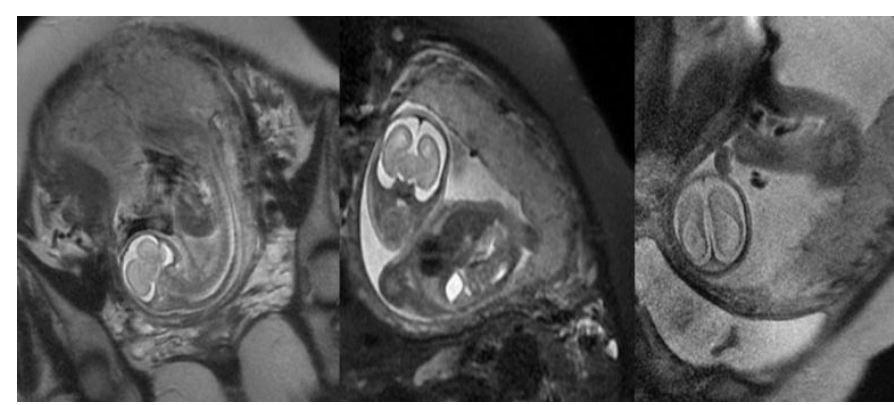

Image 3) MRI of fetus axial and coronal T2W images showing widely seprated and dilated ventricles, open sylvian fissures, small vermis suggestive of corpus callosum dysgensis with corpus callosum dysgensis

\section{Conclusions}

MRI is superior to USG in diagnosing CNS anomalies of the fetus. MRI can add additional diagnostic information to sonography in fetuses for which prenatal intervention is being considered. MRI should be done after 18 weeks of gestation, first of all to obtain satisfactory images at an optimal stage of fetal development and secondly so that termination if required can be carried out by 20 weeks of gestation as per the MTP act of India, 1971. So far, no deleterious effect on either the mother or the baby has been shown, even with high magnetic fields. The information provided by MRI allows for improved patient counselling, which may be used to assist patients in the decision to continue or discontinue a pregnancy, or to facilitate planning the mode of delivery and perinatal care.

\section{References}

1. Temtamy SA, Meguid NA, Mazen I, Ismail SR, Kassem NS, Bassiouni. A R. genetic epidemiological study of malformations at birth in Egypt. East Mediterr Health J, 4 (1998), pp. 252-259.

2. Chen CJ. Perinatal mortality and prevalence of major congenital malformations of twins in Taipei city Taiwan. Acta Genet Med Gemellol (Roma), 41 (2-3) (1992), pp. 197203
3. Drugan A, Krause B, Canady A, Zador I, Sacks A, Evans M. The natural history of prenatally diagnosed cerebral ventriculomegaly. JAMA, 261 (1989), pp. 1785-1788

4. Berry KNS, Throrpe-BesstonRSJ, Gosden C. Fetal lateral cerebral ventriculomegaly: associated malformations and chromosomal defects. Fetal DiagnTher, 5 (1990), pp. 5-14

5. Levine D, Barnes D,Madsen JR, W. LiEdelman RR. Fetal central nervous system anomalies: MR imaging augments sonographic diagnosis. Radiology, 204 (1997), pp. 35-64

6. Coakley FV, Glenn OA, QayyumA, Barkovich AJ, GolsteinR, Filly RA, et al. Fetal MRI: a developing technique for the developing patient. AJR Am J Roentgenol, 182 (242-53) (2004), p. 55

7. Twickler DM, Magee KP, Caire J, M. Zaretsky JL. Fleckenstein RM. Ramus. Second-opinion magnetic resonance imaging for suspected fetal central nervous system abnormalities. Am J ObstetGynecol, 188 (2003), pp. 492-496.

8. Fogliarini, CK. Chapon CF et al. Assessment of cortical maturation with prenatal MRI. PartI: normal cortical maturation. EurRadiol, 15 (2005), pp. 1671-1685.

9. Nadine G, Kathia $\mathrm{CH}$, Sylvianne $\mathrm{C}$ et al. Magnetic resonance imaging and the detection of fetal brain anomalies, injury, and physiologic adaptations. CurrOpin Obstet Gynecol, 18 (2006), pp. 164-176

10. McCarthy SM, Filly RA, Stark DD, Callen PW, Golbus MS, Hricak H. Magnetic resonance imaging of fetal anomalies in utero: early experience. AJR, 145 (1985), pp. 677-682

11. Levin D, Hatbu H, Gaa J, Atkinson M, Edelman R. Fetal anatomy revealed with fast MR sequences. AJR, 167 (1996), pp. 905908. 